\title{
Probiotics in the Treatment of Diverticular Disease. A Systematic Review
}

\author{
Edith Lahner $^{1}$, Cristina Bellisario ${ }^{2}$, Cesare Hassan ${ }^{3}$, Angelo Zullo ${ }^{3}$, Gianluca Esposito ${ }^{1}$, Bruno Annibale ${ }^{1}$
}

\author{
1) Dipartimento Medico- \\ Chirurgico di Scienze Cliniche \\ e Medicina Traslazionale, \\ Sant'Andrea Hospital, School \\ of Medicine, University \\ Sapienza, Rome; \\ 2) Department of Cancer \\ Screening, Centre for \\ Epidemiology and Prevention \\ in Oncology (CPO), \\ University Hospital Città \\ della Salute e della Scienza di \\ Torino, Turin; \\ 3) Digestive Endoscopy Unit, \\ Ospedale Nuovo Regina \\ Margherita \\ Rome, Italy
}

\begin{abstract}
Background \& Aims: Diverticular disease is a common gastrointestinal condition. Low-grade inflammation and altered intestinal microbiota have been identified as factors contributing to abdominal symptoms. Probiotics may lead to symptoms improvement by modifying the gut microbiota and are promising treatments for diverticular disease. The aim of this study was to systematically review the efficacy of probiotics in diverticular disease in terms of remission of abdominal symptoms and prevention of acute diverticulitis. Methods: According to PRISMA, we identified studies on diverticular disease patients treated with probiotics (Pubmed, Embase, Cochrane). The quality of these studies was evaluated by the Jadad scale. Main outcomes measures were remission of abdominal symptoms and prevention of acute diverticulitis.

Results: 11 studies ( 2 double-blind randomized placebo-controlled, 5 open randomized, 4 non-randomized open studies) were eligible. Overall, diverticular disease patients were 764 ( $55.1 \%$ females, age 58-75 years). Three studies included patients with symptomatic uncomplicated diverticular disease, 4 studies with symptomatic uncomplicated diverticular disease in remission, 4 studies with complicated or acute diverticulitis. Mainly (72.7\%) single probiotic strains had been used, most frequently Lactobacilli. Follow-up ranged from 1 to 24 months. Interventions were variable: in 8 studies the probiotic was administered together with antibiotic or anti-inflammatory agents and compared with the efficacy of the drug alone; in 3 studies the probiotic was compared with a high-fibre diet or used together with phytoextracts. As an outcome measure, 4 studies evaluated the occurrence rate of acute diverticulitis, 6 studies the reduction of abdominal symptoms, and 6 studies the recurrence of abdominal symptoms. Meta-analysis on the efficacy of probiotics in diverticular disease could not be performed due to the poor quality of retrieved studies.

Conclusion: This systematic review showed that high-quality data on the efficacy of probiotics in diverticular disease are scant: the available data do not permit conclusions. Further investigation is required to understand how probiotics can be employed in this condition.
\end{abstract}

Key words: diverticular disease - treatment - probiotics - symptomatic uncomplicated diverticular disease - systematic review.

Abbreviations: DD: diverticular disease; IBS: irritable bowel syndrome; PRISMA: Preferred Reporting Items for Systematic Reviews and Meta-Analyses; RR: relative risk.

\section{INTRODUCTION}

Diverticular disease (DD) is the fifth most important gastrointestinal disease in terms of healthcare costs in Western countries, with the highest rates in the United States and Europe. All age groups can be affected but prevalence increases with age, and cases in younger individuals are more likely to be complicated [1-3]. Diverticular diseases is a term used to include diverticulosis and diverticulitis and it may denote a clinically significant and symptomatic condition or asymptomatic diverticulosis.

In the vast majority of individuals, colonic diverticula remain symptomless (diverticulosis), while approximately $20 \%$ of them develop symptoms, including recurrent abdominal pain or discomfort, bloating, changing in bowel habits (symptomatic diverticular disease). Only about $4 \%$ of patients develop acute diverticulitis, contradicting the common belief that diverticulosis has a high rate of progression $[4,5]$.

A significant proportion of patients with DD complain of symptoms resembling or overlapping those of irritable bowel syndrome (IBS), making a clear differentiation between the two conditions challenging [6-8]. It has been reported that, beyond abdominal symptoms, symptomatic DD is associated with a reduced quality of life, in particular vitality and emotional 
health $[9,10]$, suggesting that DD may be experienced as a chronic illness marked by ongoing abdominal symptoms and psychosocial distress $[11,12]$. A recent report showed that patients with acute diverticulitis may be at risk for subsequent development of IBS, a condition for which the term postdiverticulitis IBS has been proposed [11], analogously to postinfectious IBS proposed some years ago [13]. Both conditions, DD and IBS, presumably share some pathophysiological factors leading to symptom generation as low-grade inflammation, visceral hypersensitivity, abnormal colonic motility, and altered intestinal microbiota [14-19]. Changes in peri-diverticular bacterial flora has been suggested as a potential key step in the pathogenesis of diverticular inflammation and abdominal symptoms in DD [15], thus making probiotics an appealing therapy for this condition $[20,21]$.

Probiotics may modify the gut microbial balance leading to health benefits due to their anti-inflammatory effects and capability to enhance anti-infection defences by maintaining an adequate bacterial colonization in the gastrointestinal tract and by inhibiting colonic bacterial overgrowth and metabolism of pathogens [22-24]. A recent systematic review and metaanalysis concluded that probiotics were effective treatments for IBS, showing that the relative risk (RR) of IBS symptoms persisting with probiotics compared with placebo was 0.79 (95\% CI 0.70-0.89) [25].

A recent consensus report stated with a $97 \%$ level of agreement, that to date there is insufficient evidence that probiotics are effective in reducing symptoms of diverticular disease [26]. Previous reviews on the use of probiotics in DD suggested that probiotics seem to be potentially useful in the management of this condition [20, 27]. In the last years, some new literature data on the role of probiotics in the management of diverticular disease have emerged. Based on this background, this study aimed to systematically review the efficacy of probiotic treatment in diverticular disease in terms of remission of abdominal symptoms and prevention of acute diverticulitis.

\section{METHODS}

\section{Study selection}

The search was conducted according to the PRISMA (Preferred Reporting Items for Systematic Reviews and MetaAnalyses) guidelines [28]. The electronic databases PubMed MEDLINE (U.S. National Library of Medicine, Bethesda, MD), EMBASE Elsevier, and Cochrane Central Register of Controlled Trials were systematically searched according to the following search strategy:

To assess all articles on colonic diverticulosis and diverticular disease of the colon: Explore colonic disease with an additional search using the key words: [(diverticulosis OR diverticular OR diverticula OR diverticulitis) AND (colon OR colonic OR sigmoid)] OR "diverticulosis, colonic" (MeSH). Combine with: probiotic OR probiotics OR synbiotic OR synbiotics OR symbiotic OR symbiotics or prebiotic OR prebiotics. Combine with: lactobacillus OR lactobacilli OR bifidobacteria OR escherichia OR saccharomyces OR casei OR paracasei OR boulardii OR rhamnosus OR helveticus OR acidophilus. Filter: NOT [Animal(MeSH)] NOT (Human(MeSH)) AND Animal(MeSH).
The search strategy excluded reviews, meta-analyses, case reports, and animal studies. The following study types were included: randomized clinical trials (blinded and/or placebocontrolled), open randomized clinical trials, non-randomized open studies. Pediatric subjects were excluded from this review. No publication date restrictions were imposed. Reports published in English, German, French, Italian, and Spanish language were considered.

Clinical studies published up to December 2015 were considered for inclusion if they described in adults $(>18$ years) with DD the efficacy of probiotic treatment with respect to baseline (i) on improvement or remission of abdominal symptoms, and/or (ii) on prevention of acute diverticulitis.

Potentially relevant articles were screened for eligibility independently in an un-blinded standardized manner by the two reviewers (E.L., B.A.), initially by abstract and then by full text when necessary to determine whether they met the inclusion criteria. In detail, reviews, letters and/or editorials were excluded on the basis of the abstract and/or title; in other cases the judgement of inclusion/exclusion was based on the evaluation of the full-text. Disagreement between reviewers was resolved by discussion. The reference lists of the identified articles as well as of identified relevant reviews were manually searched for additional studies that may have been overlooked using computer-assisted search strategy.

\section{Data extraction}

We developed a data extraction sheet, pilot-tested it on three randomly-selected included studies, and refined it accordingly. One review author (E.L.) extracted the data from included studies and the second author (B.A.) checked the extracted data. Disagreements were resolved by discussion between the two review authors. The following information was extracted from each included paper: 1) author and year of publication; 2) characteristics of probiotic strains (single/multiple, type); 3) characteristics of study participants (number, mean age and gender); 4) type of diverticular disease; 5) study type and treatment arms; 6) type of intervention; 7) follow-up; 8) outcome data (remission of abdominal symptoms; occurrence of acute diverticulitis) / efficacy of intervention; 9) adverse effects of probiotics arms; 11) single or multiple centre.

\section{Statistical analysis}

Originally, a meta-analysis was planned in order to provide a numerical estimate of the overall effect of interest taking into consideration as outcome measure (effect size) the proportion of patients who showed a positive response to probiotics treatment with respect to baseline or with respect to controls defined as the complete regression or the absence of recurrence of abdominal symptoms. Due the heterogeneity of the retrieved studies, meta-analysis was not considered applicable. The efficacy of the interventions reported in the retrieved studies was described in a qualitative manner.

\section{Quality assessment}

The two reviewers evaluated the quality of all included studies using the Jadad scale for randomized controlled trials [29]. This scale awards a maximum of five points to each study. The considered categories are randomization, blinding of outcome 


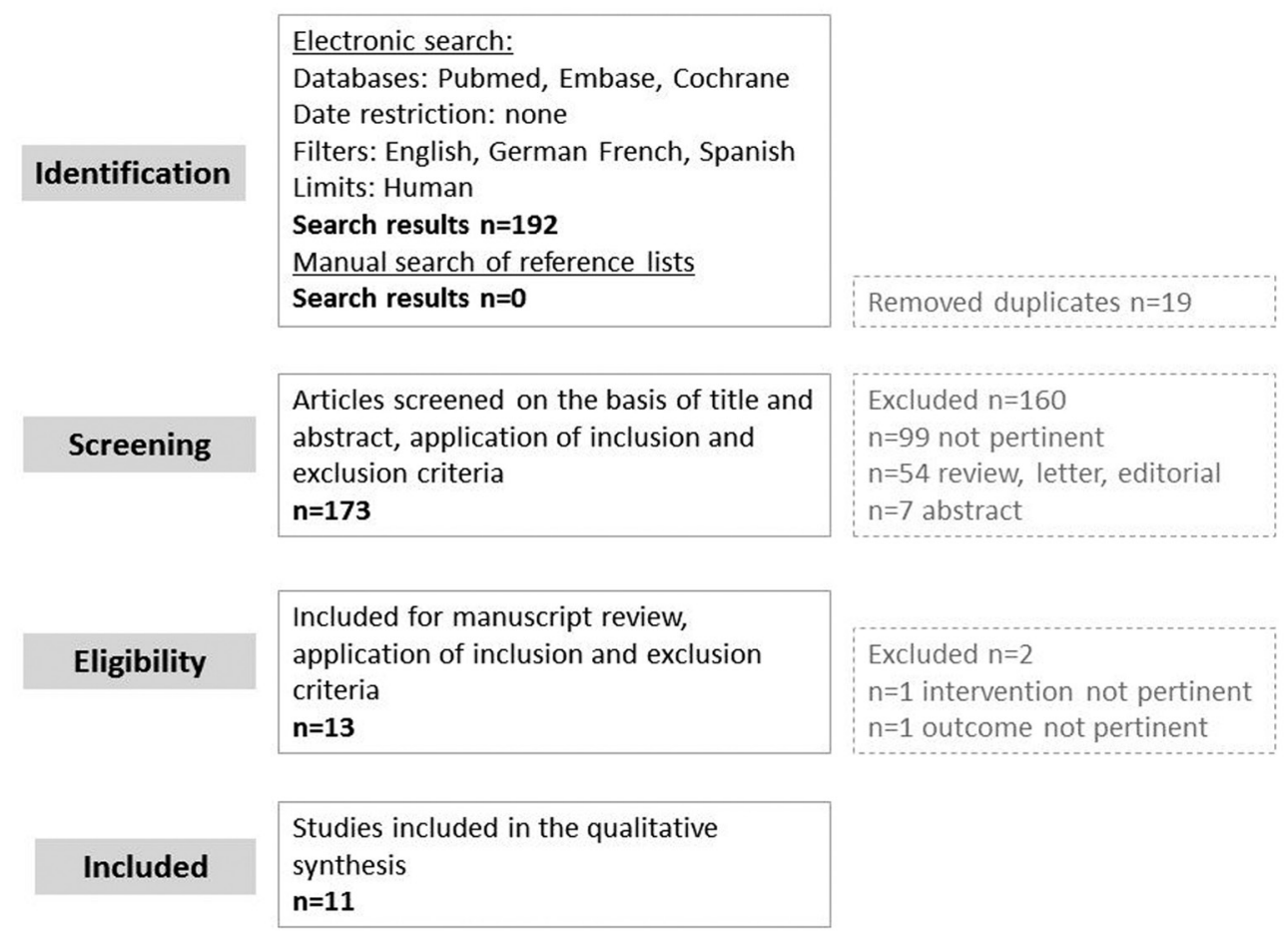

Fig. 1. Flow-chart of study selection.

assessment, description of withdrawals and dropouts, description and appropriateness of randomization and blinding. A study can be awarded a maximum of one point for each category. Discrepancy in quality assessment was discussed and resolved by two reviewers.

\section{RESULTS}

\section{Search results}

The electronic search strategy identified a total of 192 records from electronic databases, 171 of which were unique (Fig. 1). These articles were screened on the basis of title and abstract and, after application of the inclusion and exclusion criteria, 13 articles were retrieved for full-paper evaluation. Of these 13 full-papers, 11 met the eligibility criteria and were subjected to data extraction [30-40]. Two studies were excluded because in one the outcome (expression of TNF-alpha in segmental colitis associated with diverticulosis) [41] and in the other the intervention (oral polybacterial lysate suspension) was not pertinent to the present study purpose [42]. Manual searching of reference lists of potentially relevant papers and reviews did not add any more articles. Thus, 11 articles were included for qualitative synthesis.

\section{Quality assessment}

Details of the quality assessment of included studies are given in Supplementary Table S1 (see Supplementary material). Of the eleven included studies, four (36.4\%) [30$32,36]$ achieved 1 point, five $(45.4 \%)$ [33-35, 37, 38] achieved 3 points, and two $(18.2 \%)$ studies $[39,40]$ achieved 5 points according to Jadad scale.

\section{Characteristics of included studies}

The main characteristics of the 11 included studies are summarized in Table I. These studies were performed over a period of 20 years, from 1993 to 2013, and five of them were more recent than 2010 [36-40]. Six studies [30-32, 34, 35, 39] were single and five $[33,36-38,40]$ were multicenter studies.

The 11 included studies investigated an overall total number of 764 patients with DD. Female gender was slightly prevalent $(\mathrm{n}=421,55.1 \%)$. Patients had a mean age over 55 years in all studies, ranging from 58 to 75 years. In particular, five studies investigated patients with a mean age $>65$ years $[30,33,35$, 37, 38].

Nine of the eleven studies were conducted in Europe, eight in Italy [30, 32-35, 3, 38, 40] and one in the Czech Republic [31]. From the remaining two studies, one was an Italian-Japanese collaboration [36] and one was performed in the USA [39].

With regard to the type of $\mathrm{DD}$, three studies included patients with symptomatic uncomplicated DD [31, 37, 38] and four studies patients with symptomatic uncomplicated DD in remission $[33,35,36.40]$. The remaining four studies investigated patients with complicated or acute diverticulitis [30, 32, 34, 39].

With regard to study type, two studies were double-blind randomized placebo-controlled trials $[39,40]$, five studies were open randomized trials $[33-35,37,38]$, the remaining were non-randomized open studies [30-32, 36].

Type of intervention, follow-up and outcome measure

With regard to the probiotics strains, in the majority of studies $(72.7 \%)$, patients were treated with a single probiotic strain $[30,31,33,35,37-40]$, and in only three studies multiple probiotic strains were employed $[32,34,36]$. Table II shows the strains of probiotics and their eventual prebiotic component used in the included studies. The most frequently investigated probiotic strains were different strains of Lactobacilli, while Bifidobacteria or other probiotic strains as Streptococcus or Escherichia were used less frequently. In three studies [36- 
Table I. Main characteristics of the 11 selected studies on probiotics treatment in diverticular disease

\begin{tabular}{|c|c|c|c|c|}
\hline Author Year (Ref) & $\begin{array}{c}\text { \# Patients / F / mean age } \\
\text { (years) }\end{array}$ & Type of diverticular disease & Study type / Arms & $\begin{array}{l}\text { Single center } \\
\text { yes/no }\end{array}$ \\
\hline Giaccari S 1993 [30] & $79 / 34 / 63$ & Complicated DD in remission & Open / 1 & Yes \\
\hline Fric P 2003 [31] & $15 / 10 / 75$ & Symptomatic uncomplicated DD & Open $/ 2$ & Yes \\
\hline Tursi A 2005 [32] & $12 / 5 / 58$ & Acute diverticular colitis & Open / 1 & Yes \\
\hline Tursi A 2006 [33] & $85 / 54 / 67$ & $\begin{array}{l}\text { Symptomatic uncomplicated DD } \\
\text { in remission }\end{array}$ & Open RT / 3 & No \\
\hline Tursi A 2007 [34] & $30 / 11 / 60$ & $\begin{array}{l}\text { Uncomplicated acute } \\
\text { diverticulitis }\end{array}$ & Open RT / 2 & Yes \\
\hline Tursi A 2008 [35] & $75 / 42 / 65$ & $\begin{array}{l}\text { Symptomatic uncomplicated DD } \\
\text { in remission }\end{array}$ & Open RT / 5 & Yes \\
\hline Lamiki P 2010 [36] & $46 / 36 / 62$ & $\begin{array}{l}\text { Symptomatic uncomplicated DD } \\
\text { in remission }\end{array}$ & Open / 1 & No \\
\hline Annibale B 2011 [37] & $50 / 32 / 65$ & Symptomatic uncomplicated DD & Open RT / 3 & No \\
\hline Lahner E 2012 [38] & $45 / 35 / 65$ & Symptomatic uncomplicated DD & Open RT / 2 & No \\
\hline Stollman N 2013 [39] & $117 / 61 / 58$ & CT confirmed acute diverticulitis & DB placebo-controlled RT / 3 & Yes \\
\hline Tursi A 2013 [40] & $210 / 101 / 62$ & $\begin{array}{l}\text { Symptomatic uncomplicated DD } \\
\text { in remission }\end{array}$ & DB placebo-controlled RT / 4 & No \\
\hline
\end{tabular}

DB: double blind; DD: diverticular disease; F: female; Ref.: reference; RT: randomized trial

38] symbiotics were used, as probiotics were combined with prebiotics, and from one study [30] this information could not be extracted.

With regard to the follow-up protocol, the studies were very variable, and the follow-up periods ranged from 1 to 24 months. Two studies observed patients for less than 6 months $[31,32]$, three studies followed patients for 6 months [36-38], five studies followed patients for 12 months [30, 33, 34, 39, 40] and one study observed patients for 24 months [35].

In addition, the interventions were variable between studies. In eight studies, the probiotic was administered together with a drug (antibiotic [rifaximin], anti-inflammatory agent as mesalamine or beclomethasone) $[30-35,39,40]$ and compared with the efficacy of the drug alone. In five studies, however, there was a probiotic treatment arm without any associated drug $[33,36-38,40]$, in three of them the probiotic arm was a control arm $[33,35,40]$, in the remaining three studies, the probiotic was compared with a high-fibre diet [37, 38] or used together with phytoextracts [36]. With regard to the outcome measures, four studies evaluated the occurrence rate of acute diverticulitis [30, 33, 36, 40], six studies assessed the reduction of abdominal symptoms [30, 31, 34, 37, 38, 39] and six studies assessed the remission of abdominal symptoms $[31,32,33,35,36,40]$. Table III summarizes the type of interventions, follow-up protocols and outcome measures of the selected studies. Due to the poor quality of studies and the heterogeneity of study design, a meta-analysis could not be performed to provide a pooled estimate of the outcome measure. Details on the efficacy of probiotics treatment in the eleven included studies are reported in Table III.

Table II. Probiotic strains employed in the 11 selected studies

\begin{tabular}{|c|c|c|}
\hline Author Year (Ref) & Strain $(s)$ & Symbiotic yes/no \\
\hline Giaccari S 1993 [30] & Lactobacillus (specific strain not reported) & Not reported \\
\hline Fric P 2003 [31] & Escherichia coli strain Nissle & No \\
\hline $\begin{array}{l}\text { Tursi A } 2005[32] \\
\text { Tursi A } 2007[34]\end{array}$ & $\begin{array}{l}\text { Streptococcus thermophilus DSM 24731, Bifidobacterium } \\
\text { longum DSM 24736, Bifidobacterium breve DSM 24732, } \\
\text { Bifidobacterium infantis DSM 24737, Lactobacillus } \\
\text { acidophilus DSM 24735, Lactobacillus plantarum DSM 24730, } \\
\text { Lactobacillus paracasei DSM 24733, Lactobacillus delbrueckii } \\
\text { subsp. bulgaricus DSM } 24734\end{array}$ & No \\
\hline $\begin{array}{l}\text { Tursi A } 2006[33] \\
\text { Tursi A } 2008 \text { [35] } \\
\text { Tursi A } 2013 \text { [40] }\end{array}$ & Lactobacillus casei subsp. DG & No \\
\hline Lamiki P 2010 [36] & $\begin{array}{l}\text { Lactobacillus acidophilus, Lactobacillus helveticus, } \\
\text { Bifidobacterium. subsp. } 420\end{array}$ & Yes: Not specified (phytoextracts) \\
\hline Annibale B 2011 [37] & Lactobacillus paracasei subsp. paracasei F19 & Yes: Glucooligosaccharides \\
\hline Lahner E 2012 [38] & Lactobacillus paracasei B21060 & Yes: Arabinogalactan-xylooligosaccharides \\
\hline Stollman N 2013 [39] & Bifidobacterium infantis 35624 & No \\
\hline
\end{tabular}


Table III. Intervention and follow-up protocol in the 11 selected studies on probiotics treatment in diverticular disease

\begin{tabular}{|c|c|c|c|c|}
\hline Author Year (Ref) & Interventions & Follow-up & Outcome measure & Efficacy of Intervention \\
\hline Giaccari S 1993 [30] & $\begin{array}{l}\text { T1: Rifaximin } 400 \mathrm{mg} \text { bid for } 7 \text { days }+ \\
\text { lactobacillus ( } 2 \mathrm{cps} \text { ) } 7 \text { days every month } \\
\text { for } 12 \text { months }\end{array}$ & 12 months & $\begin{array}{l}\text { Reduction of abdominal } \\
\text { symptoms } \\
\text { Occurrence of acute } \\
\text { diverticulitis }\end{array}$ & $\begin{array}{l}70 / 79 \text { pts regression of symptoms, } \\
4 / 79 \text { reduction of symptoms } \\
\text { 0/79 diverticulitis }\end{array}$ \\
\hline Fric P 2003 [31] & $\begin{array}{l}\text { T1: probiotic }+ \text { dichlorchinolinol + } \\
\text { active coal tablets } \\
\text { T2: dichlorchinolinol + active coal } \\
\text { tablets for } 1 \text { week }\end{array}$ & 3-6 weeks & $\begin{array}{l}\text { Reduction of abdominal } \\
\text { symptoms } \\
\text { Length of remisssion }\end{array}$ & $\begin{array}{l}\text { Significant reduction of abdominal } \\
\text { symptoms in } \mathrm{T} 1(\mathrm{p}<0.001) \\
\text { Obtained remissions were shorter in } \mathrm{T} 2 \\
\text { compared to } \mathrm{T} 1(\mathrm{p}<001)\end{array}$ \\
\hline Tursi A 2005 [32] & $\begin{array}{l}\text { T1: beclomethasone dipropionate } 10 \\
\text { mg/day for } 4 \text { weeks + probiotic for } 2 \\
\text { weeks, followed by beclomethasone } \\
\text { dipropionate } 5 \mathrm{mg} / \text { day for } 4 \text { weeks + } \\
\text { probiotic for } 2 \text { weeks }\end{array}$ & 8 weeks & $\begin{array}{l}\text { Reduction of abdominal } \\
\text { symptoms }\end{array}$ & $\begin{array}{l}\text { Significant reduction of symptoms score } \\
(\mathrm{p}<0.001)\end{array}$ \\
\hline Tursi A 2006 [33] & $\begin{array}{l}\text { T1: mesalamine } 1.6 \mathrm{~g} / \text { day; T2: probiotic } \\
15 \text { days/month; T3: mesalamine } 1.6 / \text { day } \\
\text { + probiotic } 15 \text { days/months }\end{array}$ & 12 months & $\begin{array}{l}\text { Remission of abdominal } \\
\text { symptoms }\end{array}$ & $\begin{array}{l}\text { 29/29 T3 pts symptom-free versus } 23 / 27 \mathrm{~T} 1 \\
\text { pts and } 23 / 29 \mathrm{~T} 2 \mathrm{pts}(\mathrm{p}<0.05) \\
1 / 84 \text { pts diverticulitis }\end{array}$ \\
\hline Tursi A 2007 [34] & $\begin{array}{l}\text { T1: balsalazide } 2.25 \mathrm{~g} / \text { day }+ \text { rifaximin } \\
800 \mathrm{mg} / \text { day } 10 \text { days, then balsalazide } \\
2.25 \mathrm{~g} 10 \text { days } / \text { months + probiotic } 15 \\
\text { days } / \text { month for } 12 \mathrm{months} \\
\text { T2: balsalazide } 2.25 \mathrm{~g} / \text { day + rifaximin } \\
800 \mathrm{mg} / \text { day } 10 \text { days, then probiotic } 15 \\
\text { days/ month for } 12 \text { months }\end{array}$ & 12 months & $\begin{array}{l}\text { Remission of acute } \\
\text { diverticulitis } \\
\text { Assessment of symptom } \\
\text { scores }\end{array}$ & $\begin{array}{l}\text { Same time in } \mathrm{T} 1 \text { andT2 }(5 \mathrm{vs} 4 \text { days }) 1 \mathrm{~T} 1 \\
\text { pts and } 2 \mathrm{~T} 2 \text { pts relapse of uncomplicated } \\
\text { diverticulitis } \\
11 / 15 \mathrm{~T} 1 \text { pts and } 8 / 15 \mathrm{~T} 2 \text { pts symptom-free } \\
(\mathrm{p}<0.01) \text { at the end of follow-up }\end{array}$ \\
\hline Tursi A 2008 [35] & $\begin{array}{l}\text { T1: Probiotic } 10 \text { days/ month }+ \\
\text { mesalamine } 800 \mathrm{mg} / \text { daily } \\
\text { T2: Probiotic } 10 \mathrm{days} / \mathrm{month}+ \\
\text { mesalamine } 1600 \mathrm{mg} / \text { daily } \\
\text { T3: Mesalamine } 800 \mathrm{mg} 10 \text { days/ month } \\
\text { T4: Mesalamine } 1600 \mathrm{mg} 10 \text { days/ } \\
\text { month } \\
\text { T5: Probiotic for } 10 \text { days a month }\end{array}$ & 24 months & $\begin{array}{l}\text { Remission of abdominal } \\
\text { symptoms }\end{array}$ & $\begin{array}{l}\text { Symptom-free at } 24 \text { months: } \\
15 / 16 \mathrm{~T} 1 \mathrm{pts} \\
12 / 13 \mathrm{~T} 2 \mathrm{pts} \\
11 / 13 \mathrm{~T} 3 \mathrm{pts} \\
8 / 10 \mathrm{~T} 4 \mathrm{pts} \\
20 / 23 \mathrm{~T} 5 \mathrm{pts} \\
\text { Probiotic vs non-probiotic arms } \mathrm{p}=0.56\end{array}$ \\
\hline Lamiki P 2010 [36] & $\begin{array}{l}\text { T1: Probiotic + prebiotic + } \\
\text { phytoextracts } 10 \mathrm{ml} \text { t.i.d.for } 6 \text { months }\end{array}$ & 6 months & $\begin{array}{l}\text { Remission of abdominal } \\
\text { symptoms } \\
\text { Occurrence of acute } \\
\text { diverticulitis }\end{array}$ & $\begin{array}{l}\text { Symptom-free at } 6 \text { months: } \\
31 / 46 \text { pts } \\
0 \text { pts diverticulitis }\end{array}$ \\
\hline $\begin{array}{l}\text { Annibale B } 2011 \\
\text { [37] }\end{array}$ & $\begin{array}{l}\text { T1: Probiotic + prebiotic ( } 2 \text { sachets daily } \\
\text { + high-fibre diet for } 14 \text { day/months for } \\
6 \text { months } \\
\text { T2: } 4 \text { sachets daily for } 14 \text { days/month + } \\
\text { high-fibre diet for } 6 \text { months } \\
\text { T3: high-fibre diet alone for } 6 \text { months }\end{array}$ & 6 months & $\begin{array}{l}\text { Reduction of abdominal } \\
\text { pain and bloating intensity }\end{array}$ & $\begin{array}{l}\text { Bloating VAS decreased significantly in } \mathrm{T} 1 \\
\text { and } \mathrm{T} 2(\mathrm{p}<0.05) \\
\text { Abdominal pain }<24 \mathrm{~h} \text { decreased in } \mathrm{T} 1 \text { and } \\
\mathrm{T} 2(\mathrm{p}>0.05)\end{array}$ \\
\hline Lahner E 2012 (38) & $\begin{array}{l}\text { T1: Probiotic + prebiotic } 1 \text { sachet daily } \\
\text { + high-fibre diet for } 6 \text { months } \\
\text { T2: High-fibre diet for } 6 \text { months }\end{array}$ & 6 months & $\begin{array}{l}\text { Reduction of abdominal } \\
\text { symptoms }\end{array}$ & $\begin{array}{l}\text { Significant decrease of abdominal pain } \\
<24 \mathrm{~h} \text { and }>24 \mathrm{~h} \text { in } \mathrm{T} 1 \text { and } \mathrm{T} 2(\mathrm{p}<0.05) ; \\
\text { Significant decrease of intensity of } \\
\text { abdominal pain and bloating in both groups } \\
(\mathrm{p}<0.05)\end{array}$ \\
\hline $\begin{array}{l}\text { Stollman N } 2013 \\
{[39]}\end{array}$ & $\begin{array}{l}\text { T1: Probiotic }+ \text { mesalamine } 2.4 \mathrm{~g} / \text { day } \\
\text { for } 12 \text { weeks } \\
\text { T2: mesalamine } 2.4 \mathrm{~g} / \text { day for } 12 \text { weeks } \\
\text { T3: placebo for } 12 \text { weeks } \\
\text { The treatment phase was followed by } \\
\text { a 9-month nontreatment observation } \\
\text { period. }\end{array}$ & 12 months & $\begin{array}{l}\text { Reduction of global } \\
\text { symptom score (GSS) of } 10 \\
\text { abdominal symptoms }\end{array}$ & $\begin{array}{l}\text { No statistical difference between treatment } \\
\text { arms in GSS at week } 12 \\
\text { At } 12 \text { months GSS stabilized at lower values } \\
\text { compared to baseline in all treatment arms, } \\
\text { no difference between treatment arms }\end{array}$ \\
\hline Tursi A 2013 [40] & $\begin{array}{l}\text { T1:Probiotic } 1 \text { sachet/ day for } 10 \text { days/ } \\
\text { month + mesalamine } 1.6 \mathrm{~g} / \text { day } \\
\text { T2: Probiotic } 1 \text { sachet day for } 10 \text { days/ } \\
\text { months + mesalamine placebo } \\
\text { T3: Probiotic placebo + mesalamine } 1.6 \\
\text { g/ day for } 10 \text { days/ month } \\
\text { T4: Probiotic placebo + mesalamine } \\
\text { placebo }\end{array}$ & 12 months & $\begin{array}{l}\text { Recurrence of abdominal } \\
\text { symptoms } \\
\text { Occurrence of acute } \\
\text { diverticulitis }\end{array}$ & $\begin{array}{l}\text { T1 } 13 / 54(24.1 \%) \\
\text { T2 } 8 / 55(14.5 \%) \\
\text { T3 5/51 }(9.8 \%) \\
\text { T4 2/50 }(4.0 \%) \\
\text { T1 vs T4 } \mathrm{p}<0.01) \\
\text { T1 } 0 / 54(\mathrm{p}<0.01 \text { vs other arms }) \\
\text { T2 } 8 / 55(14.5 \%) \\
\text { T3 7/51 }(13.7 \%) \\
\text { T4 23/50 }(46.0 \%) \\
\text { 6/50 T4 pts and } 1 / 55 \text { T2 pts, no cases in T1 } \\
(\mathrm{n}=54) \text { and } \mathrm{T} 3(\mathrm{n}=51) \mathrm{pts}\end{array}$ \\
\hline
\end{tabular}

$\mathrm{T} 1$ = treatment $\operatorname{arm} 1 ; \mathrm{T} 2$ treatment $\operatorname{arm} 2$; T3 treatment arm 3; T4 treatment arm 4; T5 treatment arm 5; pts = patients 


\section{Adverse effects}

Nine studies did not observe any adverse effects related to the probiotic treatment $[30,31,33-38,40]$. In one study adverse effects were not reported [32] and in one study [39] a relatively high proportion of adverse effects was present in all treatment arms (probiotic 39\%, mesalamine $47 \%$ and placebo $41 \%$ ).

\section{DISCUSSION}

This systematic review represents an attempt to provide an updated measure of evidence on the efficacy of probiotics in $\mathrm{DD}$, in terms of symptoms control and prevention of acute diverticulitis. To our knowledge this is the first systematic review to collect all available data on the use of probiotics in DD. Previous reviews on probiotics in DD were performed some years ago (2009 and 2010), but they did not perform a systematical search of the literature, nor a meta-analysis and they included only four and seven studies, respectively. These suggested that probiotics seem to be potentially useful in the management of this condition $[4,27]$.

This systematic review was conducted applying the rigorous methodology according to PRISMA guidelines [28], the used search strategy was reported in full, and to enhance the yield of computer-based electronic database searching, the reference lists of relevant papers and reviews were manually searched. No date restriction was given and reports in English, German, French, Italian, and Spanish language were taken into consideration.

However, several limitations, largely arising from the nature of the included studies available for qualitative synthesis, impair the results of this systematic review. The overall number of retrieved studies was relatively low, the quality of included studies was relatively poor, as only two of the included studies were double-blinded randomized controlled trials, and study designs were heterogeneous making a meta-analysis not applicable. Moreover, five of the eleven included trials had been performed by the same authors. The follow-up periods in the single studies were very variable. The probiotic strains employed as treatment were very different as were the treatment protocols with regard to timing, dosage or combination with other drugs. Specific strains of probiotics may have different effects in patients with DD, and pooling different studies using different strains may not be a suitable method to evaluate their efficacy. The limited number of included studies was too low to analyze single probiotic strains. Also the type of DD was not homogeneous between studies as some studies investigated patients with uncomplicated DD and other studies patients with acute diverticulitis in remission. Some studies evaluated the maintenance of remission of abdominal symptoms, while other studies investigated the reduction of abdominal symptoms. All these variables may potentially influence the clinical response to probiotic treatment.

Data emerging from the qualitative synthesis of the retrieved studies clearly show that a meta-analysis on the efficacy of probiotics from these studies is not applicable to establish if probiotic treatment may be relevant in DD. However, with all the limits above described, the efficacy of probiotics in DD reported in the single controlled studies seem to show an apparent trend to a positive clinical response on abdominal symptoms or their recurrence, especially in patients with symptomatic uncomplicated DD [31- 34, 37-40] (Table III). One possible explanation of this apparent clinical effect in the single studies lies in the fact that a significant proportion of patients with DD complain of symptoms resembling or overlapping those of IBS [6-8]. This further increases the difficulty to evaluate a possible efficacy of probiotic treatment on abdominal symptoms in patients with DD since probiotics have been shown to be effective treatment for IBS compared with placebo in a recent systematic review and meta-analysis [25].

\section{CONCLUSION}

This systematic review showed that there remains still a paucity of evidence for the efficacy of probiotics in DD and high-quality data on efficacy of probiotics in DD are scant. Available data do not allow definite conclusions. Further investigation is required to understand how probiotics can be employed in this condition.

Conflicts of interest: The authors declare that there is no conflict of interest with regard to this work.

Authors' contributions: E.L. designed the study, contributed to the selection of the studies, to the extraction of data, performed the statistical analysis and wrote the article. C.B. contributed to the selection of the studies by performing database searching. H.C. and A.Z. contributed to revision of statistical analysis and critically revised the manuscript. G.E. contributed to the to the selection of the studies and extraction of data. B.A. contributed to conception and design of the study, to the selection of the studies, to the extraction of data and to final revision of the manuscript. All authors approved the final draft submitted.

Acknowledgements: This work was funded in part by grants from the University Sapienza Rome 2013, grant number 000323/2013. The authors declare that there is no conflict of interest with regard to this work that they should disclose. We thank Tiziana Mattei and collaborators, the librarians of University Sapienza of Rome, for providing support for the literature search.

Supplementary material: To access the supplementary material visit the online version of the J Gastrointestin Liver Dis at http://www.jgld. ro/wp/archive and http://dx.doi.org/10.15403/.

\section{REFERENCES}

1. Parra-Blanco A. Colonic diverticular disease: pathophysiology and clinical picture. Digestion 2006; 73 (Suppl 1): 47-57. doi: $10.1159 / 000089779$

2. Sandler RS, Everhart JE, Donowitz M, et al. The burden of selected digestive diseases in the United States. Gastroenterology 2002; 122: 1500-1511. doi: 10.1053/gast.2002.32978

3. Jeyarajah S, Faiz O, Bottle A, et al. Diverticular disease hospital admissions are increasing, with poor outcomes in the elderly and emergency admissions. Aliment Pharmacol Ther 2009; 30: 1171-1182. doi: 10.1111/j.1365-2036.2009.04098.x 
4. Sheth AA, Longo W and Floch MH. Diverticular disease and diverticulitis. Am J Gastroenterol 2008; 103: 1550-1556. doi: 10.1111/j.1572-0241.2008.01879.x

5. Shahedi K, Fuller G, Bolus R, et al. Long-term risk of acute diverticulitis among patients with incidental diverticulosis found during colonoscopy. Clin Gastroenterol Hepatol 2013; 12: 1609-1613. doi: 10.1016/j. cgh.2013.06.020

6. Simpson J, Neal KR, Scholefield JH, Spiller RC. Patterns of pain in diverticular disease and the influence of acute diverticulitis. Eur J Gastroenterol Hepatol 2003; 15: 1005-1010.

7. Annibale B, Lahner E, Maconi G, et al. Clinical features of symptomatic uncomplicated diverticular disease: a multicenter Italian survey. Int J Colorectal Dis 2012; 27: 1151-1159. doi: 10.1007/s00384-012-1488-5

8. Cuomo R, Barbara G, Andreozzi P, et al. Symptom patterns can distinguish diverticular disease from irritable bowel syndrome. Eur Clin Invest 2013; 43: 1147-1155. doi: 10.1111/eci.12152

9. Bolster LT, Papagrigoriadis S. Diverticular disease has an impact on quality of life-results of a preliminary study. Colorectal Dis 2003; 5: 320-323. doi: 10.1046/j.1463-1318.2003.00458.x

10. Comparato G, Fanigliulo L, Aragona G, et al. Quality of life in uncomplicated symptomatic diverticular disease: is it another good reason for treatment? Dig Dis 2007; 25: 252-259. doi: 10.1159/000103896

11. Cohen E, Fuller G, Bolus R, et al. Increased risk for irritable bowel syndrome after acute diverticulitis. Clin Gastroenterol Hepatol 2013 12: 1614-1619. doi: 10.1016/j.cgh.2013.03.007

12. Strate LL, Modi R, Cohen E, Spiegel BM. Diverticular disease as a chronic illness evolving epidemiologic and clinical insights. Am J Gastroenterol 2012; 107: 1486-1493. doi: 10.1038/ajg.2012.194

13. Spiller R, Garsed K. Postinfectious irritable bowel syndrome. Gastroenterology 2009; 136: 1979-1988. doi: 10.1053/j.gastro.2009.02.074

14. Humes DJ, Simpson J, Smith J, et al. Visceral hypersensitivity in symptomatic diverticular disease and the role of neuropeptides and low grade inflammation. Neurogastroenterol Motil 2012; 24: 318-e163. doi: 10.1111/j.1365-2982.2011.01863.x

15. Simpson J, Scholefield JH, Spiller RC. Origin of symptoms in diverticular disease. Br J Surg 2003; 90: 899-908. doi: 10.1002/bjs.4277

16. Bassotti G, Battaglia E, Spinozzi F, Pelli MA, Tonini M. Twenty-four hour recordings of colonic motility in patients with diverticular disease. Evidence for abnormal motility and propulsive activity. Dis Colon Rectum 2001; 44: 1814-1820. doi: 10.1007/BF02234460

17. Clemens CH, Samsom M, Roelofs J, van Berge Henegouwen GP, Smout AJ. Colorectal visceral perception in diverticular disease. Gut 2004; 53: 717-722. doi: 10.1136/gut.2003.018093

18. Camilleri M, McKinzie S, Busciglio I, et al. Prospective study of motor sensory, psychologic, and autonomic functions in patients with irritable bowel syndrome. Clin Gastroenterol Hepatol 2008; 6: 772-781. doi $10.1016 / j . c g h .2008 .02 .060$

19. Bonfrate L, Tack J, Grattagliano I, Cuomo R, Portincasa P. Microbiota in health and irritable bowel syndrome: current knowledge, perspectives and therapeutic options. Scand J Gastroenterol 2013; 48: 995-1009. doi: 10.3109/00365521.2013.799220

20. Sheth A, Floch M. Probiotics and diverticular disease. Nutr Clin Pract 2009; 24: 41-44. doi: 10.1177/0884533608329230

21. White JA. Probiotics and their use in diverticulitis. J Clin Gastroenterol 2006; 40: S160-S162. doi: 10.1097/01.mcg.0000225504.67547.d9

22. Sanders ME. Probiotics: definition, sources, selection, and uses. Clin Infect Dis 2008; 46 Suppl 2: S58-S61. doi: 10.1086/523341

23. Sullivan A, Nord CE. Probiotics and gastrointestinal disease. J Intern Med 2005; 257: 78-92. doi: 10.1111/j.1365-2796.2004.01410.x
24. Gill HS. Probiotics to enhance anti-infective defences in the gastrointestinal tract. Best Practice Res Clin Gastroenterol 2003; 17: 755-773. doi: 10.1016/S1521-6918(03)00074-X

25. Ford AC, Quigley EMM, Laci BE, et al. Efficacy of prebiotics, probiotics, and synbiotics in irritable bowel syndrome and chronic idiopathic constipation: systematic review and meta-analysis. Am J Gastroenterol 2014; 109: 1547-1561. doi: 10.1038/ajg.2014.202

26. Cuomo R, Barbara G, Pace F, et al. Italian consensus conference for colonic diverticulosis and diverticular disease. United European Gastroenterol J 2014; 5: 413-442. doi: 10.1177/2050640614547068

27. Narula N, Marshall JK. Role of probiotics in management of diverticular disease. J Gastroenterol Hepatol 2010; 25: 1827-1830. doi 10.1111/j.1440-1746.2010.06444.x

28. Moher D, Liberati A, Tetzlaff J, Altman DG; PRISMA Group. Preferred reporting items for systematic reviews and meta-analyses: the PRISMA statement. PLoS Med 2009; 6: e1000097. doi: 10.1371/journal. pmed.1000097

29. Jadad AR, Moore RA, Carroll D, et al. Assessing the quality of reports of randomized clinical trials: Is blinding necessary? Control Clin Trials 1996; 17: 1-12. doi: 10.1016/0197-2456(95)00134-4

30. Giaccari S, Tronci S, Falconieri M, Ferrieri A. Long-term treatment with rifaximin and lactobacilli in post-diverticulitic stenoses of the colon. Eur Rev Med Pharmacol Sci 1993; 15: 29-34.

31. Fric P, Zavoral M. The effect of non-pathogenic Escherichia coli in symptomatic uncomplicated diverticular disease. Eur J Gastroenterol Hepatol 2003; 15: 313-315.

32. Tursi A, Brandimarte G, Giorgetti GM, Elisei W. Beclomethasone dipropionate plus VSL\#3 for the treatment of mild to moderate diverticular colitis: an open pilot study. J Clin Gastroenterol 2005; 39: 644-645.

33. Tursi A, Brandimarte G, Giorgetti GM, Elisei W. Mesalazine and/ or Lactobacillus casei in preventing recurrence of symptomatic uncomplicated diverticular disease of the colon: a prospective, randomized, open-label study. J Clin Gastroenterol 2006; 40: 312-316. doi: 10.1097/01.mcg.0000210092.77296.6d

34. Tursi A, Brandimarte G, Giorgetti GM, Elisei W, Aiello F. Balsalazide and/or high-potency probiotic mixture (VSL\#3) in maintaining remission after attack of acute, uncomplicated diverticulitis of the colon. Int J Colorectal 2007; 22: 1103-1108. doi: 10.1007/s00384-0070299-6

35. Tursi A, Brandimarte G, Giorgetti GM, Elisei W. Mesalazine and/or Lactobacillus casei in maintaining long-term remission of symptomatic uncomplicated diverticular disease of the colon. Hepatogastroenterology 2008; 55: 916-920.

36. Lamiki P, Tsuchiya J, Pathak S, et al. Probiotics in diverticular disease of the colon: an open label study. J Gastrointestin Liver Dis 2010; 19: 31-36.

37. Annibale B, Maconi G, Lahner E, De Giorgi F, Cuomo R. Efficacy of Lactobacillus paracasei sub. paracasei F19 on abdominal symptoms in patients with symptomatic uncomplicated diverticular disease: a pilot study. Minerva Gastroenterol Dietol 2011; 57: 13-22.

38. Lahner E, Esposito G, Zullo A, et al. High-fibre diet and Lactobacillus paracasei B21060 in symptomatic uncomplicated diverticular disease. World J Gastroenterol 2012; 18: 5918-5924. doi: 10.3748/wjg.v18. i 41.5918

39. Stollman N, Magowan S, Shanahan F, Quigley EM; DIVA Investigator Group. A randomized controlled study of mesalamine after acute diverticulitis. J Clin Gastroenterol 2013; 47: 621-629. doi: 10.1097/ MCG.0b013e31828003f6 
40. Tursi A, Brandimarte G, Elisei W, et al. Randomised clinical trial: mesalazine and/or probiotics in maintaining remission of symptomatic uncomplicated diverticular disease a double-blind, randomized, placebo-controlled study. Aliment Pharmacol Ther 2013; 38: 741-751. doi: 10.1111/apt.12463

41. Tursi A, Elisei W, Brandimarte G, et al. Tumour necrosis factoralpha expression in segmental colitis assocaited with diverticulosis down-regulates after treatment. J Gastrointestin Liver Dis 2011; 20: 365-370.

42. Dughera L, Serra AM, Battaglia E, Tibaudi D, Navino M, Emanuelli G. Acute recurrent diverticulitis is prevented by oral administration of a polybacterial lysate suspension. Minerva Gastroenterol Dietol 2004; 50: 149-153. 